\title{
La teoría platónica del éros en la República*
}

\author{
MARÍA ANGÉLICA FIERRO \\ Consejo Nacional de Investigaciones Científicas y Técnicas \\ (CONICET-Argentina) \\ msmariangelica@yahoo.co.uk
}

\begin{abstract}
Resumen: Intentamos demostrar aquí que en la República se desarrollan ciertos puntos de la concepción platónica del éros sugeridos, pero no explicados, en el Banquete: a) En el Banquete, éros se transforma en intenso deseo universal por lo bueno, el cual se manifiesta en los distintos individuos de diversas formas (Bq. 205d1-9). De acuerdo con nuestra interpretación, esta idea sugerida en el Banquete es ampliada en la psicología de la República. b) Por otra parte, en Bq. 210a1-212a7 se delinea una "escalera amorosa" —el amor a los bellos cuerpos; luego, a las bellas costumbres; posteriormente, a las bellas ciencias y, por último, a la Belleza-, pero sin esclarecer a qué refieren estos niveles "eróticos". Mostramos aquí cómo el programa de educación completo de la República puede entenderse como una expansión de esto, expresado en el Banquete en forma programática.
\end{abstract}

Palabras clave: Eros, alma, Banquete, República

\begin{abstract}
Here, I intend to show that some aspects of the platonic conception of eros which are hinted at in the Symposium receive further development in the Republic, mainly: a) In the Symposium eros is conceived like the intense, universal desire for the good, which is focused in different individuals in different ways (Symp. 205d1-9). According to my interpretation, this idea is explained in the psychology of the Republic. b) In addition to this in Symp. 210a1-212a7 an "erotic ladder" is traced: the love for beautiful bodies; afterwards, for beautiful habits; then, for beautiful sciences; finally, for Beauty itself. However, no enlightenment about what these different "levels" refer to is provided. Here I show how the whole program of education in the Republic constitutes a systematic development of these ideas of the Symposium.
\end{abstract}

Key words: Eros, soul, Symposium, Republic

*El presente artículo retoma y desarrolla más ampliamente algunas de las ideas centrales de mi tesis de doctorado "Plato's Theory of Desire in the Symposium and the Republic" (University of Durham-UK, 2003), realizada bajo la supervisión del Prof. C.J. Rowe, a quien agradezco por las discusiones estimulantes sobre mi trabajo. También quiero dar las gracias a quienes realizaron el arbitraje ciego de este escrito por sus comentarios críticos para afinar la argumentación y presentación.

Las traducciones de los textos griegos son mías, de acuerdo a las ediciones del TLG que en el caso de Platón sigue la de Burnet 1905-1907. Los textos citados son de la República de Platón, a no ser que se indique lo contrario. 


\section{Introducción}

Si bien es cierto que en cada una de sus obras Platón adopta, como frecuentemente se ha señalado, una perspectiva irrepetible y única para el tratamiento del tema que lo ocupa, esto no impide, que, teniendo en cuenta las diferencias de cada caso, sea posible a veces iluminar parcialmente un diálogo con otro. ${ }^{1}$ Frente a intérpretes que entienden que en la República el deseo aparece, a diferencia del Banquete, contrapuesto a la razón, ${ }^{2}$ es mi propósito demostrar aquí que en aquel escrito, aunque desde un punto de partida y de interés distintos, se desarrollan y amplían ciertas ideas sugeridas en el Banquete en relación con la concepción platónica del éros, a saber:

(a) En el Banquete, el éros no es fundamentalmente, tal como se lo entendía en la cultura griega, el deseo sexual e intenso por un individuo en particular, sino que se transforma en el éros universal por lo bueno que constituye cada existencia humana, si bien, en los distintos individuos, este amor a lo bueno puede estar focalizado de diversas formas (Bq. 205d1-9) y no alcanzar necesariamente su máxima expresión como "amor a la sabiduría". ${ }^{3}$ En la interpretación aquí propuesta, la República explicaría esta idea sugerida en el Banquete. De acuerdo con esta lectura, el núcleo de la psicología de la República se encuentra expresado en la imagen hidráulica del alma trazada en 6. 485d6-8, según la cual hay dos corrientes de deseo fundamentales y opuestas en nosotros: la de los apetitos y la de la razón. A la luz de este modelo básico es posible reinterpretar la teoría tripartita del alma del libro 4 . Así, dos de las partes o aspectos -lo logistikón o "racional", con su deseo por la verdad y lo auténticamente bueno, y lo epithymetikón o "apetitivo", con su deseo de placeres sensibles- se corresponden con

${ }^{1}$ Un buen resumen sobre las distintas maneras de leer los diálogos de Platón puede encontrarse en Annas 2003, pp. 33-38. Al respecto puede verse también Bowen 1988. Kahn (1996) se refiere especialmente a la íntima conexión entre forma y contenido en la obra platónica.

${ }^{2}$ Véanse al respecto Frede 1993, pp. 409 y ss., y Parry 1996, p. 215. Nussbaum (1986, p. 201) aborda este punto de manera parecida a la de los autores mencionados en cuanto que considera que en la República hay una dicotomía entre la razón y la pasión, la cual en el Banquete se presenta dramáticamente como dos modos de vida alternativos y en el Fedro se decide a favor de la pasión. Cornford (1950) propone, pero no desarrolla, una relación entre la República y el Banquete similar a la aquí propuesta.

${ }^{3}$ Es conveniente aclarar que la concepción del éros de Platón, si bien implica lo que comúnmente se entiende por "amor platónico" — “amor idealizado y sin relación sexual" hacia alguien (DRAE) —, no tiene a éste como su sentido fundamental. 
los dos cauces de deseo divergentes de la imagen hidráulica. Por otro lado, la tercera parte - lo thymoeidés o "irascible"-, con su deseo de victoria y predominio, resulta ser un monto de energía erótica bivalente en cuanto que puede ya fortalecer la corriente de deseo de la razón, ya estar al servicio de los apetitos, o bien, habiendo actuado al inicio de forma autónoma, finalmente puede verse debilitada por ellos. ${ }^{4}$ Lo que es esencialmente cada ser humano depende, entonces, de la configuración de estas fuentes primeras de motivación, representadas por las partes del alma, y esto determina o bien que la razón lidere nuestra vida con su deseo por la verdad $-\mathrm{y}$, con ello, sea posible la satisfacción del deseo universal por lo verdaderamente bueno-, o bien que la corriente de los apetitos nos domine y aleje, en mayor o menor medida, de esta aspiración universal.

(b) Por otra parte, en el Banquete se delinea una "escalera amorosa" -el amor a los bellos cuerpos; luego, a las bellas costumbres; posteriormente, a las bellas ciencias y, por último, a lo Bello en sí (Bq. 210a1212a7) - a través de la cual se podría desplegar el éros en su máxima expresión: como "filosofía" o "amor a la sabiduría". Sin embargo, en el Banquete queda sin ser esclarecido a qué refieren concretamente estos niveles "eróticos". El programa de educación de la República puede entenderse como una expansión de esto expresado allí en forma programática. En coherencia con la interpretación que proponemos de la teoría psicológica de la República, la educación temprana de los guardianes estaría orientada a configurar correctamente las fuentes primarias de motivación - los tres aspectos del alma $-{ }^{5}$ y a desarrollar una familiaridad con lo bello (3. 401b1-d3), tanto respecto del alma, considerada como superior al cuerpo (3. 402d1-e1), como fundamentalmente respecto de las costumbres y las virtudes (4. 444d13-e5; 3. 402d14). En este sentido, sería equiparable a la comprensión de la belleza

${ }^{4}$ Se puede explicar así de modo coherente la función de lo thymoeidés en oposición a la interpretación de Robinson (1995, p. 45), quien dice que la parte irascible es un concepto oscuro y contradictorio en la República, y a Penner (1971), quien la considera en realidad un aspecto de la parte apetitiva. El trabajo de Hobbs (2000) es uno de los más importantes en los últimos tiempos para revalorizar la función de lo irascible, si bien no se centra, como se hace aquí, en su funcionamiento en la dinámica erótica del alma.

${ }^{5}$ A diferencia de Gill (1985, y 1996, p. 269, esp. n. 96), quien sostiene que no hay desarrollos en la República respecto de la educación de lo epithymetikón, mostraremos sintéticamente aquí cómo la educación primaria está dirigida no sólo a lo irascible y lo racional del alma, sino también a lo apetitivo. Véanse más adelante las pp. 41-43. 
de los cuerpos y, luego, de las almas y las costumbres planteada en el ascenso erótico del Banquete. ${ }^{6}$ Por otra parte, la educación avanzada desarrollaría el "amor a las bellas ciencias" a través del estudio de las ciencias matemáticas (7. 522c1-531e1), hasta llegar a la comprensión de la unidad y el parentesco entre las mismas (7. 531c9-d4) y, luego, a través de la ciencia suprema de la dialéctica (6.504e4-5) se captaría la interconexión entre las Ideas unificadas en la Idea del Bien (6. 509b610; 6. 511b3-c2; 7. 533b6-e2), a la manera en que las cosas bellas se unifican en la Belleza. ${ }^{7}$

Con el desarrollo de (a)-(b) esperamos contribuir de diversos modos a los debates ya existentes: por un lado, sugerir puntos de vista distintos de interpretación; ${ }^{8}$ por el otro, proponer que un modo de entender la República es considerarla, tomada en su conjunto, un desarrollo de la teoría del éros del Banquete, lo cual abre, creemos, perspectivas hermenéuticas respecto de otras obras de Platón, como el Fedro.

\footnotetext{
${ }^{6}$ Raven (1965, pp. 119-130) ya había sugerido esto, pero sin desarrollarlo de modo sistemático.

${ }^{7}$ Hay un aspecto más respecto del cual la República expande y recrea ideas del Banquete. En Bq. 212a2-7 se afirma que quien alcance la contemplación de la Belleza será capaz de procrear "virtudes auténticas" en lugar de simples "imágenes de virtud", y también que le será posible alcanzar una inmortalidad post-mortem similar a la de los dioses (véase, sobre este último punto, Fierro 2001a, contra Hackforth 1950, al que sigue Sedley 1999, p. 310, n. 2). Fundamentalmente, el libro 10 de la República proporciona elucidación sobre estas ideas que permanecen sin desarrollar en el Banquete. De acuerdo con las reflexiones sobre la "producción" o poíesis en 10. 595a1 y ss., podría entenderse que aquel que llega al conocimiento de la Belleza obraría, en el dominio ético, de modo similar al dios-artesano que, con vistas a las Ideas, crea cosas "reales" (ónta), y no meras "apariencias" (phainómena) (10. 596e4). En ese sentido, el hombre conocedor de las Ideas sería productor de "verdadera perfección" y no de "imitaciones" de la virtud. Por otra parte, la idea de inmortalidad divina insinuada en Bq. 212a2-7 es desarrollada más ampliamente a través del mito escatológico del final de la República (10. 614b2-621d3), donde se especula sobre cómo el hombre que logra la generación de auténtica justicia a través del conocimiento puede además esperar, como recompensa de los dioses, una existencia similar a la de ellos, sin cuerpo mortal (véase O'Brien 1984 en relación con esta línea de interpretación), así como la reencarnación regular en una vida filosófica. Sin embargo, esta relación entre el Banquete y la República no es posible desarrollarla aquí y esperamos exponerla en futuros trabajos.

${ }^{8}$ Véanse las nn. 1-7 supra. Las diferencias con otros intérpretes en aspectos puntuales se señalan en cada caso a lo largo del artículo.
}

Diánoia, vol. LIII, no. 60 (mayo 2008). 


\subsection{La constitución de la existencia humana en el éros del Banquete}

Como explica Dover, ${ }^{9}$ en la cultura griega éros ${ }^{10}$ refiere primariamente no tanto a la mera ansia sexual indeterminada, sino al deseo por un compañero sexual específico, remitiendo en general a lo que relacionamos con el fenómeno del enamoramiento. Se trata de un deseo caracterizado por su intensidad y la exclusividad del objeto que puede colmarlo, ${ }^{11}$ y originado en la belleza -tò kállos- que se descubre en el amado. ${ }^{12}$ Significa, entonces, algo diferente de epithymía, que refiere al mero apetito, vinculado primariamente a las necesidades fisiológicas como la sed, el hambre, y que no requiere ser saciado con objetos específicos, con tal que la carencia sea de algún modo cubierta. ${ }^{13}$ Éros implica además, a diferencia de epithymía, un mayor ímpetu y magnitud en el desear. ${ }^{14}$ Por otra parte, según los testimonios literarios, éros puede ser tanto una fuerza aniquiladora y destructiva que avasalla la vida de un individuo, ${ }^{15}$ como una energía unificadora y crea-

${ }^{9}$ Dover 1980, p. 1 . Al respecto, véase también Hunter 2004, pp. 15-20.

${ }^{10}$ Más precisamente Eros y éros, puesto que los griegos se referían tanto al sentimiento como al dios. Véase Dover 1980, p. 1.

${ }^{11}$ Así en el Canto 3 de la Ilíada, versos 441-446, éros significa el apremiante deseo que embarga a Paris de hacer el amor a una mujer en particular: la bella Helena.

${ }^{12}$ Véase Safo, Frag. 16, 1-4.

${ }^{13}$ Véase en Tuc., G.Pel. 2.52.1, la referencia a los que, medio muertos, rondaban alrededor de todas las fuentes debido a su "deseo de agua" (toû hýdatos epithymía), o en 7.84.2 la mención de los soldados atenienses apremiados "por su deseo de beber" (toû pieîn epithymía). La distinción entre éros y epithymía no debe tomarse, sin embargo, como absoluta, tal como señala Dover (1978, p. 43). Por otra parte, epithymía también puede significar "deseo" en general, y éros referir a un tipo o especie de deseo en particular. Éros es también distinto de philía, que es el término que quizá más adecuadamente podríamos traducir por "amor" o "cariño" de todo tipo (véase Jen. Hierón, 3.7). Así, LSJ propone la traducción "affectionate regard", además de la habitual de "friendship" (véase LSJ, u.v. philía).

${ }^{14}$ Tal como leemos en el fragmento 7 del sofista Pródico (DK 84 B 7), éros es "doble epithymía".

${ }^{15}$ La Medea de Eurípides ofrece quizá, en este sentido, el ejemplo más estremecedor. En el fragor de la pasión erótica que la consume, la princesa y hechicera Medea no sólo primero mata y destripa a su propio hermano para facilitar la huida de su amado, Jasón, con el vellocino de oro perteneciente al reino de su padre en Colcis: además, no duda después en inmolar incluso a sus hijos comunes, a fin de cobrarse venganza, ya que se siente despechada por la traición de Jasón al abandonarla y desposar una princesa corintia. Véase también en el Hipólito de Eurípides el éros 
tiva, incluso a nivel político ${ }^{16}$ y cósmico. ${ }^{17}$ Por último, cabe agregar que en el círculo de la aristocracia intelectual de Platón éros se desarrolla principalmente a través de la relación homosexual, en la cual, según las pautas de su tiempo, ${ }^{18}$ un hombre mayor y experimentado - el amante o erastés - cortejaba a un agraciado y talentoso jovencito -el amado o erómenos, también llamado paidiká — ofreciéndole, a cambio de los favores sexuales del muchachito, su guía para alcanzar la "perfección" o areté, es decir, en este contexto, el éxito individual y público.

En el Banquete existe una apropiación y, al mismo tiempo, una transformación y ampliación de esta concepción de la pasión erótica.

Al comienzo del discurso de Sócrates/Diotima (Bq. 201d1-204c6) se realiza una descripción general del éros ${ }^{19}$ según la cual éste posee una naturaleza híbrida o intermedia (metaxý ) en cuanto que es esencialmente carente de su objeto - lo bello y lo bueno- y, a su vez, provisto de recursos para procurárselo. Su carácter metaxý lo hace no sólo un "intermedio", sino, crucialmente, un "intermediario" que vincula el ámbito humano con lo bello, lo bueno, lo divino e inmortal, y que encuentra su máxima expresión en el anhelo del filósofo por la verdad. ${ }^{20}$ A continuación de esta caracterización, en Bq. 204d1-206b1 se realiza una argumentación más específica por la cual éros, como en la concepción habitual, sigue siendo un deseo intenso que domina la vida de un individuo, pero, en lugar de estar dirigido fundamentalmente a una persona amada en particular, la corriente erótica está encauzada hacia lo bueno y determina, según cuál sea su foco de orientación,

devastador que posee a Fedra por su hijastro Hipólito (véase Hipol. vv. 27-28, 3840, 727, 775) y la caracterización de éros en Soph., Ant. vv. 781-801.

${ }^{16}$ Esto es propio de la comedia aristofánica, particularmente en algunas como la Lisístrata (véase Lis. vv. 550-554).

${ }^{17}$ Véase Hes., Teog., vv. 115-125.

${ }^{18}$ Sobre este punto, véanse Dover 1978, Foucault 1986, y Davidson 1997.

${ }^{19}$ En esta descripción se recupera lo ya establecido a través del diálogo SócratesAgatón en Bq. 199c3-201c9 y algunas tesis que han sido anticipadas en forma no crítica en los discursos anteriores al de Sócrates. A su vez, en el Lisis encontramos formuladas algunas de las tesis generales sobre el objeto y el sujeto de deseo que aparecen en el Banquete. Sobre este último punto, puede verse Kahn 1996, pp. 264-267.

${ }^{20}$ Véase Fierro 2007. Sobre la noción platónica de intermediario en general, puede verse Souilhé 1919, y sobre el éros como sintetizador de lo humano y lo divino, el trabajo clásico de Robin (1908). En Hornsby 1956-1957, Halperin 1992, y Fierro 2001b se muestra, de distinto modo, cómo el carácter metaxý del éros se expresa también en la estructura narrativa del Banquete.

Diánoia, vol. LIII, no. 60 (mayo 2008). 
distintos tipos de existencias. Este argumento tiene fundamentalmente dos momentos.

En primer lugar, luego de acordarse que el que desea las cosas bellas desea la posesión de ellas, se pregunta qué se busca con esta posesión, y Diotima solicita a Sócrates un cambio de lo bello por lo bueno: "Pero [contesta]... como si alguien, tras sustituir el término 'bello' y utilizando el de 'bueno' [metabalòn antì toû kaloû thoî agathô̂ chrómenos], preguntara..." (Bq. 204e1-2). ${ }^{21}$ A través de esta sustitución se puede concluir más fácilmente que el deseo de todo ser humano de la posesión permanente de lo bueno tiene como objetivo la felicidad (Bq. 204e6205a3). Ahora bien, lo que aquí nos importa es que la redescripción del éros por lo bello como éros por lo bueno lo vuelve claramente universal, de modo tal que todos somos amantes y no sólo quienes están enamorados. En otras palabras, todos estamos enamorados, no de alguien, sino del bien.

-Ahora bien, este deseo y amor [tèn boúlesin kaì tòn érota] ¿crees que es común a todos los seres humanos, que todos quieren que las cosas buenas les pertenezcan siempre [pántas tagathà boúlesthai hautoîs eînai aeí ], o acaso cómo dices que es?

—Así pienso..., que es común a todos.

-Pues bien ¿por qué, entonces, Sócrates,... no afirmamos que todos los hombres aman [pántas erân], si es que en realidad todos aman las mismas cosas, y las aman siempre, sino que decimos que algunos aman pero otros no?

—También a mí... me sorprende eso. (Bq. 205a5-b3)

Este argumento permite una extensión y transformación del éros en al menos dos sentidos respecto de su significación habitual:

- por un lado, hay una ampliación de los sujetos de deseo: el éros comprende a todos los seres humanos y no únicamente a los enamorados en el sentido corriente;

- por el otro, hay una redefinición del objeto: el éros está dirigido no a una persona bella en particular, sino a lo bueno en general, que pasa a ser lo que absorbe el interés de la vida de cada persona.

${ }^{21}$ En la cultura griega, tò kalón - lo bello- y tò agathón -lo bueno- aparecían ya íntimamente vinculados en el concepto de la aristocracia de kalokagathía o "caballerosidad", según el cual lo bueno y al mismo tiempo bello era aproximarse lo más posible, a través de las prerrogativas naturales y fundamentalmente de la educación, al ideal de hombre propio de esta clase social (sobre esta idea, véase Jaeger 1942). Véase también la n. 24, infra. 
Este último aspecto establece sin duda una conexión entre lo que se formula en este pasaje y algo expresado en los diálogos socráticos; a saber, que todos deseamos el bien. ${ }^{22}$ Si bien éros no es ya aquí específicamente "deseo sexual", no se trata tampoco de que se transforme en un mero deseo genérico de lo bueno: el deseo universal de lo bueno, en tanto se lo describe como éros, preserva sus atributos distintivos de intensidad, ${ }^{23}$ dominio de la vida del individuo y atracción por la belleza, en cuanto aspecto más patente de lo bueno. ${ }^{24}$

Esta ampliación del éros como algo constitutivo de cada existencia humana es reforzada a través de la comparación de este término con el término poíesis. Así como el término poíesis puede entenderse en el sentido estrecho de producción artística, o la acepción más amplia de producción en general, del mismo modo éros puede referir no sólo a la pasión erótica por otro individuo, sino que es, ante todo, aquello que orienta nuestra existencia en una determinada dirección. Así, en Bq. 205b4-d8 se sugiere que este amor que nos concierne a todos se expresa de distintos modos según qué es para nosotros lo bueno, es decir, aquello en lo que centramos la pasión de nuestras vidas:

${ }^{22}$ Sobre la universalidad del deseo de lo bueno puede verse, p.ej., Gorg. 468b y Eut. 278e y ss. Véase también aquí la n. 26, infra.

${ }^{23} \mathrm{Al}$ respecto de la ampliación del concepto de éros, no creemos que en el discurso de Sócrates-Diotima siga siendo meramente "deseo sexual", a veces sublimado, a veces no (véase Santas 1988, p. 34), ni tampoco que se transforme en simple deseo genérico de lo bueno (véase Rowe 1998, pp. 181-182), sino que hay un doble movimiento en el argumento por el cual se amplía al deseo universal de lo bueno, pero se conservan los rasgos de éros de intensidad, atracción por la belleza y efecto absorbente en la existencia del individuo "enamorado". Así, el deseo sexual pasa a ser una de sus manifestaciones.

${ }^{24}$ Si bien es cierto que, como afirma Rowe (1998, p. 179), en el Banquete: "Whatever S. or Diotima thinks about the precise relationship between the good and the beautiful is never made clear" [nunca queda claro lo que Sócrates o Diotima piensan acerca de la relación precisa entre lo bueno y lo bello], es posible hacer ciertas conjeturas al respecto. De acuerdo con lo que se dice en 6. 508e3-509a7, el Bien es un género más amplio que incluye lo Bello; a su vez, en el Fedro 250b5-6, 250c8d3 se sugiere que la Belleza sería el aspecto más "visible" o "resplandeciente" de lo Bueno, es decir, su aspecto más obvio y atractivo. Llevado esto al contexto del argumento que estamos analizando, esto significaría algo así como que la belleza es aquello que nos atrae o seduce de lo bueno. Cabe también señalar que en la reformulación de éros con vistas a sus actividades o érga, la posesión es reemplazada por la procreación, y la belleza pasa de ser el objeto de deseo propiamente dicho, a funcionar como el medio para que la productividad erótica tenga lugar (Bq. 206b7 y ss.). Sobre la relación entre lo bueno y lo bello, la proporción y la verdad, véase también Fil. 65a1 y ss. 
—... Pues, en efecto, habiendo apartado una cierta especie de amor [tô̂ érotós ti eîdos], la llamamos 'amor' [érota], atribuyéndole el nombre del todo, y aplicamos erróneamente a las restantes especies otros nombres.

[...] En resumen, todo deseo de las cosas buenas y de ser feliz [pâsa he tôn agathôn epithymía kaì toû eudaimoneîn] es 'el amor (éros) grandísimo y engañoso' para todos. Pero de algunos, los cuales se dirigen a él de muy diversas formas [pollacheî] —ya sea siguiendo los negocios, la afición a la gimnasia o la filosofía-, no se dice que amen [erân] ni que sean amantes [erastaí ]. En cambio, los que se conducen y esfuerzan según una sola forma se apoderan del nombre del todo — 'amor' [érota] — y sólo de ellos se dice que aman y son amantes.

"Lo bueno" cumple aquí una función análoga a lo que sería el fin último de nuestra vida —en forma similar al prôton phílon del Lisis (219c7-5; 220b1-7)—, siendo más precisamente en este contexto lo que constituye el foco de nuestro anhelo. Ahora bien, ¿por qué si todos amamos lo mismo - es decir, lo bueno-, cada existencia puede estar centrada en diversos objetos de amor - la gimnasia, los negocios, la filosofía- y resultar entonces en distintos tipos de existencia? A continuación intentaremos demostrar cómo la psicología de la República ofrece una explicación de esta diversa organización posible de éros en la vida humana.

2.2. El deseo universal del bien y la imagen hidráulica del alma de la República

En el Libro 6 de la República se afirma, al igual que en el Banquete, el carácter universal del deseo de lo bueno, más exactamente de lo verdaderamente bueno:

pero, en relación con las cosas buenas, para nadie poseer cosas aparentes es ya satisfactorio, sino que buscan las cosas reales, y todos desprecian aquí al punto la apariencia [agathà dè oudenì éti arkeî tà dokoûnta ktâsthai, allà tà ónta zetoûsin, tèn dè dóxan entaûtha éde pâs atimázei]. (6. 505d7-9)

Sin embargo, aunque todos deseamos el auténtico bien, no siempre podemos obtenerlo, por cuanto no siempre tenemos una clara y correcta comprensión de qué es lo bueno. ${ }^{25}$

${ }^{25}$ En 6. 505d11-506a2 se refiere a lo bueno del siguiente modo: "lo que persigue toda alma y por cuya causa hace todas las cosas, adivinando intuitivamente que es algo, pero estando en dificultades y no siendo capaz de aprehender suficientemente qué es ni de hacer uso de una creencia estable, tal como sí ocurre respecto de otras cosas. Debido a esto también fracasa si hay algo beneficioso a partir de otras cosas..."

Diánoia, vol. LIII, no. 60 (mayo 2008). 
Lo que veíamos entonces en $B q$. 205b4-d8 podría explicarse a la luz de este pasaje del siguiente modo: aunque todos deseamos el bien, no hay coincidencia en el objeto central de nuestro amor porque no siempre comprendemos apropiadamente qué es lo bueno.

Sin embargo, el que nuestra existencia no esté dirigida a lo bueno y no se logre un adecuado discernimiento del auténtico bien no se debe únicamente a un error epistemológico. La teoría del alma de la República muestra que para lograr el correcto entendimiento de la verdadera naturaleza de lo bueno y el estado cognoscitivo que le corresponde -inicialmente la orthé dóxa u opinión correcta; posteriormente, si fuera posible, la ciencia dialéctica que culmina en la captación de lo Bueno- es necesaria una organización determinada de las fuentes de motivación básicas, representadas en las dos corrientes fundamentales de deseo del aparato psíquico y en el papel de las partes del alma en relación con las mismas. ${ }^{26}$

En la República se presenta una imagen "hidráulica" del alma, ${ }^{27}$ a la que se le ha prestado menos atención que a la división tripartita, pero que resulta fundamental para comprender apropiadamente qué tipo de modelo psicológico se está planteando. Según esta imagen, en el ser humano existen dos corrientes principales de deseo, las cuales

${ }^{26}$ La diferencia fundamental entre el intelectualismo ético de los llamados diálogos socráticos o de juventud, donde también se sostiene que todos deseamos lo auténticamente bueno, y la propuesta de la República como diálogo de la madurez de Platón, sería, a nuestro juicio, la siguiente: en ambos casos se trata de cuán correcta y fundamentada es la comprensión de lo verdaderamente bueno en cada individuo, pero mientras en los diálogos tempranos ésta sería una cuestión puramente intelectual, en una teoría psicológica como la de la República, como mostraremos, el conocimiento de lo realmente bueno no depende únicamente del apropiado desarrollo de la razón, sino también de una adecuada organización de las restantes partes del alma, de modo tal que no obstaculicen, y, en el caso de la parte irascible, incluso colaboren con la parte racional. Mientras que interpretaciones como las de Rowe (1998, p. 181) suponen que en la República hay una ruptura respecto del planteamiento intelectualista del deseo universal del bien de los diálogos socráticos, donde incluye al Banquete, nuestra interpretación es más bien que hay una continuidad en la medida en que República explica más complejamente, pero sin contradecir lo que se enuncia en los diálogos socráticos al respecto. Sobre el intelectualismo socrático puede verse el trabajo de Segvic (2000).

${ }^{27}$ Platón no utiliza la palabra "alma" (psyché ) de modo consistente (véase Annas 2003, cap. 6, "My Soul and Myself", pp. 65-76). Aquí asumimos que el sentido fundamental de este término en la República es lo que en términos de filosofía de la mente se llamaría el "yo interno", mientras que el sôma o "cuerpo" sería nuestro aspecto físico y externo. 
son divergentes de modo tal que la mayor afluencia de una supone una merma de la otra.

Pero, por cierto, para el que en verdad los deseos ${ }^{28}$ se inclinan fuertemente hacia una cierta dirección, sabemos, de algún modo, que son para ése más débiles hacia otras cosas, como una corriente desviada de su curso hacia allá. (6. 485d6-8)

En la referencia subsiguiente al verdadero filósofo, ${ }^{29}$ queda claro que los dos cauces son, por un lado, la corriente de la razón que fluye hacia la sabiduría, y, por el otro, la corriente de los apetitos que se desliza hacia los placeres corporales.

De acuerdo a la imagen hidráulica del alma, la psyché resulta ser, entonces una suerte de quantum de deseo, el cual, si es canalizado en una dirección, queda restringido en la cantidad que puede dedicar a otro tipo de objetos de deseo. Lo crucial para la concepción platónica del ser humano es que, dado que el acrecentamiento de un cauce supone el debilitamiento del otro, entonces la razón, para alcanzar su objeto de deseo - el conocimiento verdadero-, no sólo requiere su propio desarrollo, sino también la reducción de los apetitos.

\section{3. Las tres partes del alma según el esquema hidráulico}

A partir de esta imagen hidráulica del alma es posible reinterpretar la más conocida, y también más desarrollada, teoría del alma tripartita de la República a fin de explicar más ampliamente tres cuestiones: en qué consistiría la divergencia fundamental entre ambas corrientes de deseo, qué determina la distribución de la energía erótica y por qué el objeto de amor - lo bueno- varía de un individuo a otro.

En conformidad con esta teoría, que se desarrolla en el libro 4 y se retoma en gran medida en los libros 8 y 9, hay tres "aspectos" (eíde) o "partes" (mére) en nuestra alma, cada una constituida por un objeto de deseo que le es propio:

- La parte apetitiva o epithymetikón está relacionada primariamente con los objetos de nuestras necesidades fisiológi-

${ }^{28}$ Aquí epithymíai refiere a deseos en general y no sólo a los apetitos, como queda claro en el pasaje subsiguiente, donde una de las corrientes es identificada con el curso correspondiente a la razón. Véase la n. 13, supra.

29 "Entonces para quien [los deseos] han fluido hacia los saberes y todo lo de ese tipo, se darían, creo, [deseos] respecto al alma y al placer del alma en sí misma, pero [estos deseos] omitirían los placeres que se dan a través del cuerpo, si fuera alguien filósofo en verdad, y no mera apariencia" (6. 485d10-e1). 
cas y, de modo derivado, con la riqueza como medio para procurase la satisfacción de estas necesidades, ${ }^{30}$ por esto es llamada "amante de la riqueza" y "amante de la ganancia" (9. 581a3-7).

- La parte irascible o thymoeidés es el aspecto del alma con el que se siente enojo, y puede ser descrita como la agresividad (4. 439e 3$)^{31}$ en el sentido de la fuerza para confrontar lo real (2. 375a11-b2), ya entendamos esto como algo externo o interno. Tiene como objeto propio de deseo la victoria y el triunfo (9. 581b2) y, de modo derivado, el honor y la fama,

- Finalmente, lo racional o logistikón es la parte con que aprendemos (9. 580d10), ${ }^{32}$ razonamos, calculamos y juzgamos (9. 582d7), ${ }^{33}$ y es "amante del aprendizaje" y "amante de la sabiduría" (9.581b5-10). Debido a este deseo constitutivo, en principio, las actividades intelectuales de esta parte - tales como razonar, aprender, juzgar - se realizarían para alcanzar su objeto de deseo, es decir, la verdad.

Veamos, entonces, más puntualmente la relación entre las tres partes a la luz de la imagen de la corriente bifurcada del alma.

\section{A. Lo apetitivo y lo racional en el esquema hidraúlico}

La parte apetitiva y la parte racional se corresponden claramente con las dos corrientes de deseo de la imagen hidráulica. Ahora bien, tomando en cuenta las características de cada una de estas partes, se puede comprender más precisamente que la divergencia entre las dos corrientes consiste en la indiferencia de los apetitos respecto de la bondad o la maldad de sus objetos de deseo (que los hace a menudo dirigirse a lo opuesto de lo verdaderamente bueno), y la tendencia de lo racional hacia el auténtico bien.

Por un lado, según 4. 439a4-7, los apetitos — tales como la sed, el hambre, los apetitos sexuales, etc.- tienen objetos no cualificados de deseo (por ejemplo, la sed no es necesariamente sed de una buena bebida, sino de una bebida en cuanto tal). En consecuencia, los objetos

${ }^{30}$ Esto no significa, sin embargo, que lo epithymetikón posea una razón instrumental (véase Lorenz 2004, pp. 110-111).

${ }^{31}$ Véase también 9. 580d10.

${ }^{32}$ Véase también 9.581 b5.

${ }^{33}$ Véase también 4. 439d5. 
de deseo de los apetitos pueden ser buenos o malos. Esto se relaciona, asimismo, con que lo apetitivo es caracterizado como alogistón o "irracional", ${ }^{34}$ lo cual puede entenderse en dos sentidos: se dirige a sus objetos en forma "bestial", ${ }^{35}$ no siendo capaz de cálculo y reflexión, y crucialmente, como señalábamos, tampoco respecto de lo bueno y lo malo; es en su esencia insaciable (4. 442a7) y sin límites, siendo incapaz de establecer el coto apropiado, es decir, de establecer lo que es bueno para sí mismo (4. 442a4-b3). ${ }^{36}$

Por el otro, lo logistikón parece ser el aspecto capaz de reconocer y desear lo bueno - no sólo respecto de sí mismo, sino también de las otras dos partes y del alma en su totalidad-, y en este sentido se opone a menudo a los deseos de lo epithymetikón, ${ }^{37}$ de acuerdo con sus cálculos: ${ }^{38}$

Pero [llamaremos a cada cual] sabio por esa pequeña parte [i.e., la parte racional] que gobierna en él y prescribe estas cosas, teniendo aquella a su vez también conocimiento de lo que es conveniente para cada una [de las partes] y para el todo común de las partes, las cuales son tres [échon aû kakeîno epistémen en hautoî tèn toû symphérontos hekástoi kaì hóloi toî koinôi sphôn autôn triôn ónton]. (4. 442c5-8)

Esta capacidad del elemento racional del alma, sugerida en el libro 4, es claramente establecida en el libro 6 a partir de $6.505 a 1$ y ss. Según este argumento que culmina en la alegoría del sol, la Idea del Bien, que es lo verdaderamente bueno, es sólo accesible a la inteligencia (noûs),

${ }^{34}$ Alogistón 4. 439d7. Nótese que alogistón implica que es irracional principalmente en cuanto que es incapaz de realizar cálculos, de ser logistikón. Nussbaum (1986, p. 205) hace una interpretación parecida: "appetites are merely brute forces reaching, insatiably and without any selectivity, each for a characteristic object" [los apetitos son fuerzas brutas que intentan alcanzar, insaciablemente y sin ninguna selectividad, cada una un objeto característico], aunque según lo que dice en p. 139, n. 5, parece inclinarse por posiciones como las de Irwin (1995, pp. 218-222) y Penner (1971). Véanse aquí las nn. 42 y 47.

${ }^{35}$ Leemos en 4. 439b4 que lo apetitivo persigue su objeto de deseo "como una bestia" (hósper theríon).

${ }^{36}$ El carácter ilimitado e insaciable de los apetitos es también desarrollado a través de la distinción en 8. 558d9 entre apetitos necesarios e innecesarios.

${ }^{37}$ Sobre la oposición entre la razón y los apetitos, véase 4. 439c9-d2.

${ }^{38}$ También en 4. 441c1-2, cuando se está distinguiendo la parte racional de la irascible, se caracteriza la parte racional como "lo que reflexiona sobre lo mejor y lo peor" (tò analogisámenon perì toû beltíonós te kaì cheíronos), es decir, como el aspecto nuestro que puede ponderar sobre lo bueno y lo malo. 
es decir, a la razón en su máxima expresión. ${ }^{39}$ La inteligencia tiene por objeto la sabiduría y la verdad, que son bellas y buenas gracias al Bien, aunque la naturaleza de lo Bueno es superior a ellas (véase especialmente 6. 509a6-8).

Entonces, el conflicto entre las "corrientes" de deseo se lo puede redescribir del siguiente modo: hay una oposición entre el "tirón" o "jalón" de los apetitos, que procuran sus objetos independientemente de su bondad o su maldad, y el "jalón" de la corriente de deseo por la verdad y lo realmente bueno, propio de la razón.

Por otra parte, la preocupación de Platón respecto de la tendencia de los apetitos a crecer ilimitadamente se corresponde con lo que muestra la organización de las corrientes eróticas en la imagen hidráulica del alma: el desarrollo desmedido de los mismos los haría acaparar la energía psíquica, debilitar así la razón y apoderarse del dominio del alma. Si, por el contrario, es la razón la que se desarrolla y los apetitos se mantienen acotados, crecen las oportunidades de la razón de alcanzar el liderazgo del alma del individuo.

Finalmente, también puede explicarse la atribución del deseo del verdadero bien a todos los seres humanos al mismo tiempo que el hecho de que los focos de amor que orientan cada vida pueden, sin embargo, divergir. Todos deseamos lo auténticamente bueno, en la medida en que todos somos seres racionales y nuestra razón desea lo que es realmente bueno. ${ }^{40}$ Sólo cuando la razón puede considerar lo que es bueno por sí misma, y sin influencia de factores ajenos a ella, hay garantía de que se dirige a su real objeto de deseo: el auténtico bien y la verdad. ${ }^{41}$ En cambio, cuando se ve sometida y corrompida por los apetitos, o por el enojo, o, más en general, por "lo que es vil en nosotros" (como las emociones excesivamente desarrolladas, las percepciones engañadoras, ${ }^{42}$ etc.), es también la racionalidad la que se declara sobre lo bueno y lo malo, pero

${ }^{39}$ Véase, p.ej., 6. 508b12-509a5: el Bien es, más exactamente, causa de la inteligencia.

${ }^{40}$ De acuerdo con la interpretación aquí propuesta, se puede explicar la aparente contradicción entre la afirmación de 6. 505d7-9, de que todos deseamos lo bueno, y lo que parece quererse establecer en 4. 439a4-7 respecto de la ceguera de los apetitos en relación con lo bueno y lo malo. Hoffman (2005) intenta disolver esta contradicción de otro modo: trata de demostrar que los apetitos también desean lo bueno. Véase también la n. 26, supra.

${ }^{41}$ Véase Cooper 1999, p. 202, n. 18.

${ }^{42}$ Así interpreto el texto de 10.602c1-608b2, siguiendo líneas ya sugeridas por Murphy (1951, p. 243), a diferencia de Penner (1971, pp. 100-108), Moline (1978, esp. pp. 10-15), Annas (1981, pp. 338-344), Janaway (1995, pp. 143-157) y Price (1995, pp. 48-72).

Diánoia, vol. LIII, no. 60 (mayo 2008). 
distorsionada por la influencia de lo cambiante y lo corporal y, por ello, no es certera en establecer lo verdaderamente bueno. ${ }^{43}$

B. El carácter bivalente de lo irascible en el esquema hidráulico del alma

Ahora bien, en este esquema es necesario agregar, además, un tercer elemento: cómo interviene en la organización de la energía erótica la parte irascible del individuo. Como veremos, esta parte es "bivalente", en el sentido de que puede o bien unirse a la parte racional y fortalecerla, o bien contribuir, de distintos modos, al desarrollo de lo apetitivo.

Los ejemplos que se dan de 4. 439e1 a 4. 441c2, a fin de establecer lo thymoeidés como una tercera parte del alma, distinta de las otras dos, ilustran estas posibles direcciones de lo thymoeidés.

Lo thymoeidés es un aliado de la razón por naturaleza, cuando, habiendo sido apropiadamente entrenado y desarrollado, ${ }^{44}$ dirige su agresividad contra los apetitos cada vez que la razón indica que lo correcto es oponerse a la pulsión de los mismos: ${ }^{45}$

¿Y no es verdad en otras ocasiones, dije, que muchas veces observamos que, cuando los apetitos (epithymíai) fuerzan a alguien en contra de la razón, [este individuo] se censura a sí mismo y se enoja (thymoúmenon) con lo que lo fuerza, y, que, como dos facciones que están sublevadas, el ardor (tòn thymòn) de tal condición se vuelve aliado de la razón? Pero que éste [i.e., el ardor] se oponga, tras haberse aliado con los apetitos, al decidir la reflexión que no hay que actuar, no creo que tú dirías haber observado [algo semejante], ni por haber acaecido una cosa tal en ti mismo, ni tampoco creo en otro. (4. 440a8-b7)

Pero lo irascible puede también oponerse a la razón cuando vemos en 4. 441a5-c2 que deseos provenientes de un enojo irracional (tò alo-

${ }^{43}$ En la descripción del oligarca, esta situación está claramente considerada cuando en 8 . 553d1-7 se refiere a cómo lo logistikón puede ser sometido a los fines de los apetitos y obligado a utilizar su capacidad de cálculo y razonamiento para perseguir fines ajenos a la razón.

44 "Siendo guardián de lo racional por naturaleza, si no ha sido corrompido por una mala educación (epíkouron òn toî logistikô̂ phýsei, eàn mè hypò kakês trophês diaphthareî)" (4. 441a2-3).

${ }^{45}$ Por eso, la virtud de la valentía o andreía es, para Platón, en principio "coraje moral", consistente en esta lucha de lo irascible contra los apetitos de acuerdo con los dictados de la razón (4. 442b11-c3): la valentía en el sentido de enfrentar a los enemigos externos del modo apropiado - es decir, cuando son enemigos de la ciudad (2. 375a11-b4; 6. 503a1-5) - es un aspecto derivado de esta valentía moral. 
gístos thymoúmenon, 4. 441c2) pueden estar en conflicto con deseos que surgen de los cálculos de la razón sobre lo que es bueno y malo (en el caso de este pasaje, el deseo de venganza de Odiseo contra los pretendientes que se han adueñado de su casa en Ítaca en su ausencia, se opone al consejo de la razón de posponer la represalia para un momento oportuno). Esto significa que, a pesar de ser un aliado natural de la razón, lo thymoeidés puede procurarse los objetos que le son propios - la victoria y el honor - sin la guía de lo racional, tal como se sugiere en 9. 590a9-b1, en referencia a la posibilidad de que el elemento "leonino" y "viperino" 46 del alma, identificado con lo irascible, crezca y se extienda en detrimento de la armonía anhelada por la racionalidad. En este caso, la agresividad de lo thymoeidés, sin apropiado entrenamiento, no lucha contra los apetitos o se apacigua, según corresponda, y al actuar de este modo favorece el crecimiento desmedido de lo epithymetikón, acabando lo irascible mismo por ser debilitado por los apetitos, los cuales convierten "al león en mono" (9.590b6-9).

El examen de la timocracia y el timócrata, es decir, el régimen y tipo de hombre gobernados por los deseos de lo thymoeidés, nos brinda más elementos. Según 8. 548b7-c2, el régimen timocrático, homólogo en su estructura al hombre timocrático, es precisamente el que está dominado por los deseos de lo irascible de triunfo y honor, pero con desprecio de lo que alimenta la razón. Este tipo de estructura política conlleva, además, como en el régimen oligárquico, un crecimiento de los apetitos (véase 8. 548a5-b1), sólo que todavía este aumento de los mismos se produce "en secreto" (hypò skótou) (8. 548a7) y "clandestinamente" (ou phanerôs) (8. 548b4-5). De manera semejante, el hombre timocrático, "amante del poder y los honores" (phílarchos... kaì philótimos), no muy interesado en las actividades que estimulan el desarrollo de la razón (8. 548e4-549a7) y, más concretamente, carente de la salvaguardia del razonamiento mezclado con educación artística (8. 549b6-7), también desarrolla con el tiempo amor por las riquezas (8. 549a9-b4). Según esto, parece ser que, entonces, el desarrollo de lo thymoeidés, sin la conducción de la razón, deriva en un dominio de los apetitos, tal como le ocurre al oligarca, en el que el elemento irascible aparece claramente sometido a lo epithymetikón (8. 553d1-7).

Por lo tanto, podemos concluir que, en este conflicto entre la corriente del alma racional y la corriente del alma apetitiva, la parte irascible a veces auxilia a la razón en su lucha contra los apetitos y, entonces, la

\footnotetext{
46 "Lo viperino" representaría las expresiones más degradadas de lo irascible (véase el comentario de Adam (1965) ad locum).
}

Diánoia, vol. LIII, no. 60 (mayo 2008). 
fortalece, pero a veces no. En caso de que haya sido apropiadamente entrenada, la parte irascible contribuye a mantener los apetitos dentro de límites apropiados, de modo tal que ayuda a despejar el terreno para que la razón crezca y opere sin obstáculos, al mismo tiempo que proporciona su propia energía erótica al canal de la razón. En cambio, cuando no cumple con su función natural de ser un aliado de la razón, dos situaciones son posibles. Una de ellas es que puede que en un comienzo la corriente de la parte irascible sea poderosa y luche por la victoria y el honor, dominando el alma de esa persona; sin embargo, por no estar apropiadamente entrenada para apoyar a la razón, terminará siendo arrastrada por la corriente de los apetitos. La segunda posibilidad es que directamente la parte irascible sea débil y de por sí considere como "lo digno de estima" el objeto de deseo propio de los apetitos, como el dinero, los placeres corporales, etc., en cuyo caso ya está contribuyendo a fortalecer la corriente de deseo de la parte apetitiva del alma. En ambos casos, cuando la parte irascible no colabora con la razón, contribuye a permitir que los apetitos se multipliquen sin límite y así dominen el alma. Puesto que lo irascible, finalmente, o bien colabora con lo racional, o bien colabora, directa o indirectamente, con los apetitos, es coherente que en la imagen hidráulica se planteen dos - no tres - corrientes de deseo fundamentales, a pesar de que lo irascible tiene, como parte del alma, su función y características propias.

En la reconstrucción que aquí propongo de la teoría del alma en la República, a diferencia de otros intérpretes, ${ }^{47}$ supongo que las funciones cognitivas están siempre a cargo de la parte racional (4. 439d5; 9. 582d1-13) y que las otras dos partes son esencialmente irracionales o alogistón (4. 439d7). Sin embargo, el deterioro o desarrollo de la razón no depende únicamente de cuánto este aspecto nuestro se haya expandido, sino también de qué tipo de crecimiento haya tenido la otra corriente de deseo. Así, por ejemplo, si los apetitos se han acrecentado excesivamente, la razón sigue estando a cargo de realizar juicios y

${ }^{47}$ La opinión más establecida al momento es, por el contrario, que los apetitos poseen cierta capacidad intelectual. Véanse, p.ej., Penner 1971; Moline 1978; Bobonich 2002, pp. 293-354; Carone 2001, y 2005; Hoffman 2005. Más matizada es la posición de Lorenz (2004). Nuestra interpretación es que la razón está siempre a cargo de proporcionar inteligibilidad, a veces actuando por sí misma y de acuerdo con sus propios fines, a veces enlazada a las demandas de lo irascible o lo apetitivo. Una lectura de este tipo impide atribuir a las partes irracionales la actividad propia de lo racional y transformarlas en homunculi, lo cual atentaría contra la unidad del alma. No es posible, sin embargo, desarrollar aquí los fundamentos de esta interpretación. 
cálculos, pero ya no puede establecer por sí misma lo que es verdaderamente bueno, sino que se ve obligada a hacerlo en función del objeto de deseo de los apetitos, tales como la satisfacción de necesidades fisiológicas o la adquisición de riquezas (8. 553d1-7). Lo mismo ocurriría si se tratara de un hombre timocrático, dominado por la corriente de deseo que tiene como objetivo la victoria o el honor: la razón debería usar su capacidad de cálculo para el alcance de estas metas. A la inversa, si la corriente de deseo de la parte racional domina el alma, esto quiere decir que, por un lado, los apetitos han sido acostumbrados, a través de un entrenamiento apropiado, a mantenerse en el límite de lo necesario para la subsistencia, y, por el otro, la parte irascible, a su vez, ha sido educada para utilizar su agresividad a fin de reprimir el crecimiento sin límite de los apetitos. En ese caso, la razón es capaz de considerar las cosas por sí misma y de intentar alcanzar la sabiduría y la verdad —los objetos de deseo que le son propios - lo más que pueda. De acuerdo con la República, este conocimiento consistiría en el conocimiento de lo que es bueno para el individuo y la comunidad conforme a la Idea del Bien.

Según esta teoría psicológica, resulta entonces que hay tres tipos fundamentales de seres humanos en los libros 8 y 9 de la República, según sus objetos de amor: el amante de la verdad (el filósofo), el amante del honor (el hombre timocrático) y el amante de la riqueza (que incluye a su vez tres tipos: el hombre oligárquico, dominado por apetitos necesarios; el hombre democrático, dominado por apetitos necesarios e innecesarios, y el tirano, dominado por apetitos innecesarios y sin ley). El filósofo, por tener su vida conducida por la parte racional, con su deseo dominante por la verdad y el verdadero bien, es el tipo de ser humano que más cerca se encuentra de alcanzar la posesión permanente de lo bueno que todos deseamos, mientras que el tirano, con su vida gobernada por un éros protector de apetitos "criminales" (9. 572e5573a2), se sitúa en el extremo opuesto.

Queda, entonces, así dilucidado lo que encontramos formulado, pero no explicado, en el Banquete: por qué, aunque todos deseamos el bien, no todos centran su vida en los mismos objetos de deseo. También por qué la expresión más acabada de éros es el ser filósofo, puesto que es a través de este tipo de vida que nos acercamos lo más posible a la posesión permanente de lo que es verdaderamente bueno. 
3. El programa educativo para el desarrollo del deseo de la verdad

3.1. Los estadios de la escalera amorosa del Banquete

Éros, de acuerdo con su naturaleza a su vez carente y provista de recursos, no puede, como sí pueden los dioses, conservar en forma continua su objeto de deseo, sino que éste, en su elusiva naturaleza, siempre se le escapa cuando cree alcanzar su posesión (Bq. 203d8-e6). La actividad propia de éros, en pos de la posesión permanente de lo bueno - y de la inmortalidad como condición de esta posesión permanente (Bq. 206e5207a4) — , resulta ser, entonces, la adquisición de una inmortalidad "vicaria", en términos de Hackforth, ${ }^{48}$ por medio de la procreación en la belleza de producciones en las que seguimos existiendo "a través de otro" (Bq. 208a7-b2). Hay dos formas de procreación accesibles a la mayoría de los mortales: por un lado, la procreación biológica o "según el cuerpo", compartida con los animales, por la cual nos inmortalizamos dejando individuos de nuestra misma especie (Bq. 206c1-207c1); por el otro, una forma superior de producción en la belleza, la procreación cultural o "según el alma", por la cual legamos obras que nos ganen fama inmortal y supervivencia en la memoria de los otros, tales como los actos de excelencia personal o política - lo que los griegos llamaban más propiamente aretaí o virtudes-, la elaboración de leyes e instituciones, o de creaciones artísticas (Bq. 208c1-209e4).

Sin embargo, hay un modo aún más acabado de conducirse en las cuestiones eróticas, que es accesible sólo a algunos pocos y que Diotima describe utilizando el lenguaje de los misterios de Eleusis en los que el iniciado atravesaba diversas etapas rituales hasta culminar en la visión de los objetos sagrados. ${ }^{49}$ En este famoso pasaje, 210a1-212a7 del Banquete, Diotima describe a Sócrates la "escalera erótica" por la cual se asciende a la contemplación de la Belleza en sí, cuyos estadios pueden ser sintetizados así:

- En primer término, el amor a los cuerpos bellos (tà kalà sómata, $B q .211 c 4)$ y la comprensión de una hermosura única e idéntica, común a todos ellos (hén te kaì tautòn... tò epì pâsin toîs sómasi kállos, Bq. 210b3);

- en segundo lugar, la apreciación de la belleza del alma como superior a la del cuerpo (en taîs psychaîs kállos timióteron, Bq. 210b7),

${ }^{48}$ Véase Hackforth 1950. Según su interpretación, éste es el único tipo de inmortalidad presente en el Banquete, lo cual es discutible, ya que en $B q$. 212a2-7 parece sugerirse también una inmortalidad post mortem (véase la n. 7 , supra).

${ }^{49}$ Véase Rowe 1998, p. 194. 
y de la hermosura común a la bellas actividades y normas (tò en toîs epitedeúmasi kaì toîs nómois kalón, Bq. 210c3-4; véase también $B q .211 c 5)$;

- luego, el amor a las bellas ciencias (tà kalà mathémata, Bq. 211c6, tàs epistémas, Bq. 210c6) y el vasto "mar" de belleza que las unifica (polỳ tò kalòn... mekéti toî par' hení...; tò polỳ pélagos. . toû kaloû, Bq. 210d1-4);

- por último, habrá quien, habiendo sido conducido correctamente (orthôs, Bq. 210e3), pueda quizá llegar a la contemplación de la divina Belleza en sí (autò tò theîon kalón, Bq. 211e3), caracterizada del siguiente modo (Bq. 211a1-b5; Bq. 211e2-4): es pura (es decir, posee como su única propiedad el ser bella sin estar mezclada con otras propiedades, tal como ocurre en las cosas concretas); absoluta (esto es, no relativa al momento, el lugar o a quien realiza el juicio de belleza); desindividualizada (es decir, no representada a través de instancias particulares); inmutable e idéntica a sí misma, divina, y de la cual las cosas bellas participan sin que la Belleza en sí crezca o disminuya.

Si bien parecen expresarse en estos estadios amorosos las etapas del desarrollo ideal del éros en su máxima manifestación, es decir, como filosofía, en el Banquete no se esclarece en qué consiste exactamente cada uno de ellos, aunque es posible esbozar una interpretación. ${ }^{50}$

En la República, con bases en la teoría del alma en los términos que hemos reconstruido anteriormente, podemos encontrar una explicación de los distintos estadios del ascenso erótico, el cual puede ser entendido como un esbozo del programa de educación temprana y de educación superior para los futuros guardianes de la pólis ideal. Este programa

${ }^{50}$ Una posibilidad es pensar que en cada estadio se alcanza la comprensión de un tipo de belleza en el sentido de entender la perfección o armonía del grupo de objetos correspondientes al mismo. Así se comprendería la belleza de los cuerpos, en el sentido de entender lo que constituye su perfección, como podría ser la proporción anatómica que hace bello a un cuerpo. Este tipo de comprensión la podría poseer de modo acabado un escultor como Fidias, por ejemplo. Luego seguiría la captación de lo que hace perfecta y armoniosa la vida de cualquier individuo y comunidad. A continuación, de lo que constituye la perfección de las ciencias, tales como la matemática, la geometría, la astronomía; es decir, lo que las hace ser acabadamente ciencias. Finalmente, en el caso de que alguien fuera capaz, lograría la percepción del principio común y fundacional de toda la belleza previa, es decir, la visión de la Belleza en sí. El conocimiento de la belleza se acrecienta en cada nivel, y en ese sentido se puede hablar de un "ascenso" o "grados de conocimiento". 
tiene como objetivo la correcta formación de las tres partes del alma de modo tal que el deseo por la verdad de la razón alcance su máximo desarrollo.

\subsection{La educación temprana: el conocimiento de la belleza física y de las normas de conducta}

Uno de los puntos centrales de la propuesta pedagógica de República es, a nuestro entender, y en coherencia con la reconstrucción aquí hecha de la teoría psicológica en esta obra, que a través de un determinado tipo de educación, las partes del alma y los deseos propios que les corresponden pueden ser desarrollados o acotados y, en algunos casos, incluso inhibidos. ${ }^{51}$

El procedimiento básico, ya sea para estimularlos, debilitarlos o atrofiarlos, sería la creación de una segunda naturaleza a través de los ejemplos que cada individuo presencia e imita desde su infancia, tal como se expresa en 3. 395d1-3:

¿O no te has dado cuenta de que las imitaciones (hai miméseis), en caso de que continuaran por largo tiempo desde temprana edad, llegan a transformarse en hábitos (éthe) y en una naturaleza (phýsin), tanto respecto del cuerpo como del discurso o del intelecto? ${ }^{52}$

En consecuencia, el período de instrucción primaria expuesto en los libros 2 y 3 de la República está concebido por Platón para lograr una correcta configuración de las fuentes de motivación de los jóvenes guardianes fundamentalmente a través de un adiestramiento en los hábitos correctos, si bien, como veremos, la parte racional empieza al mismo tiempo a incorporar contenidos verdaderos que en la educación superior podrán ser desarrollados a través de una instrucción propiamente intelectual y especializada. El objetivo de esta etapa educativa es que

${ }^{51}$ En el libro 9, el fomento, debilitamiento o inhibición de los deseos constitutivos de cada parte del alma a través de la educación, ya en el hombre justo o el injusto, se expresa a través de imágenes tales como "alimentar" (trepheîn) (9.589b2), "desnutrir" (limoktoneîn) (9. 589a1), "fortificar" (poieîn ischyrón)"(9. 588e6), "debilitar" (poieîn asthenê) (9.589a1), "domesticar" (tithaseueîn) (9.589b3), "dar rienda suelta" (anieîn) (9.590a6).

${ }^{52}$ La polémica teoría del arte imitativo de los libros 3 y 10 de la República (al respecto de este debate, véase Janaway 1995) supone que la imitación (mímesis) tiene un papel fundamental en la formación del carácter del individuo no sólo a través de las producciones de los artistas, sino, de modo más general, a través de las conductas de los otros que el niño observa cotidianamente. 
se creen las posibilidades psíquicas para que la razón pueda asumir el liderazgo en el alma de ese individuo.

Las características relevantes de ese periodo de educación temprana acerca del tema que nos ocupa se pueden resumir del siguiente modo:

a) Se entrenan los deseos de las partes irracionales del alma - la parte apetitiva y la parte irascible- a través de un proceso de habituación. La poderosa corriente de los apetitos - tales como el hambre, la sed, la ambición- con tendencia a desarrollarse en exceso y arrastrar el alma en dirección opuesta a la razón, se controla acostumbrándose a mantener esos apetitos dentro de los límites de lo que es necesario mediante un apropiado entrenamiento, como una dieta conveniente (3. 403e9 y ss.; 8. 559a11 y ss.); el abastecimiento mínimo para cubrir las necesidades materiales, como el techo y refugio, y la abolición de la propiedad privada (3. $415 \mathrm{e} 4$ y ss.). ${ }^{53}$ Así, puestos dentro de apropiadas restricciones, se minimiza la obstrucción que los apetitos pueden ocasionar en la búsqueda de la razón de lo que es verdadero y bueno.

Por otra parte, se desarrolla la agresividad de la parte irascible a través de actividades tales como la gimnasia y la caza (3. 410b5-8; 8. 549a5-7), pero orientándola de un modo específico, a fin de que la persona aprenda a utilizar la agresividad para resistir el "tirón" de los apetitos (4. 440b1 y ss.), luche contra los enemigos del estado (2. 375b9-c4) y se mantenga firme en las convicciones correctas que le han sido inculcadas (3. 442b11-c3; 4. 429b8-c2). De este modo, la parte irascible ejerce la función que le es propia de ser un aliado de la razón y contribuye a fortalecer la corriente que se dirige al verdadero bien.

b) En cuanto a la mousiké o educación artística, también contribuye indirectamente a la habituación de las dos partes irracionales en tanto que provee, a través de la forma y el contenido ${ }^{54}$ de las historias que escuchan los jóvenes guardianes, ejemplos y pautas de moderación

${ }^{53}$ Pensamos entonces, a diferencia de Gill (véase la n. 5, supra) que hay en la República formulaciones respecto de la educación de los apetitos, si bien no son tan sistemáticas como la educación artística destinada a lo racional, y la educación física dirigida a lo irascible.

${ }^{54}$ Se prefiere la narración a la imitación directa. Se seleccionan también los ritmos musicales dorio y frigio, más adecuados a la promoción de la racionalidad y valentía, descartando los modos lidio, mixolidio y jónico, por incentivar estados emocionales no deseables. También son censurados instrumentos como la flauta, admitiéndose solamente la lira y la cítara. Véase 3. 397a y ss. y 3. 398d-399e. La lógica de esta propuesta educativa supone una correspondencia entre las estructuras musicales y la estructura del alma en cuanto que ambas se basan en determinadas 
y valentía. Pero, sobre todo, la mousiké está dirigida a incentivar el amor a la verdad propio de la parte racional del alma, puesto que este deseo, aun existiendo de modo incipiente en todas las personas, no se desarrolla sin la apropiada educación artística, tal como leemos en 3. 411c9-d5:

¿Pero qué cuando no hiciera ninguna otra cosa [que hacer ejercicio físico] ni tomara parte de ninguna manera de la Musa [i.e., de la educación artística]? ¿No es que, aun en el caso de que hubiera en su alma algo que ama aprender (ti... philomathés), al no adquirir el gusto por el aprendizaje y la investigación, ni participar del razonamiento o de algún otra expresión artística, [esta parte] se vuelve débil, embotada y estúpida, por no ser avivada ni alimentada ni purgada de sus percepciones sensibles?

De acuerdo con este principio de promover el desarrollo de la "parte que ama aprender", los guardianes, desde su tierna infancia, adquieren creencias correctas, ${ }^{55}$ aunque todavía de manera irreflexiva, así como también cierta afinidad con lo invariable (3. 397b6-c1; 3. 399e8400a3), que para Platón está relacionado con lo que es más real y verdadero, tales como la inmutabilidad de los números y, sobre todo, de las Ideas, que serán posteriormente objeto reflexivo de estudio para quienes accedan a la educación superior.

El resultado final que se espera de este periodo primero de formación de las fuentes de motivación de los jóvenes guardianes claramente se superpone con los dos primeros niveles de la escalera amorosa del Banquete:

- Su amor a la sabiduría se habría desarrollado de tal modo que se habrían familiarizado con lo que es bueno, bello y gracioso, y también habrían aprendido a reconocerlo, aunque de modo no reflexivo. Tal como leemos en 3. 401c4-d3, éste debe ser el objetivo de los buenos artistas que eduquen con su arte a los jóvenes guardianes en esta etapa de su vida:

proporciones matemáticas, lo cual encuentra fundamento y desarrollo en la teoría del alma de Ti. 34b10-36d7.

${ }^{55}$ Sobre la necesidad de dar ejemplos de control de sí mismo y moderación, así como de evitar impartir modelos opuestos a éstos, pueden verse los siguientes pasajes de la República: 3. 386a1-387b6; 3. 390a8-c8; 3. 395b8-d3; 3. 390d7-391c6; ideas correctas acerca de lo divino, 3. 382d5-e11. Los guardianes son instruidos en la verdad: 2. 376e11-377b9; 3. 391d3-e2; lo que aprenden es la "opinión verdadera" o dóxa alethé: $3.412 \mathrm{e} 10$ y ss. 
¿Pero no se deberá buscar a aquellos hacedores de talento, capaces de seguir el rastro de la naturaleza de lo bello y lo gracioso, a fin de que, como los que habitan una región sana, los jóvenes reciban provecho de todo, de dondequiera sea que les llegara algo, a partir de las obras bellas [tôn kalôn érgon], ya a la vista, ya a los oídos, como la brisa de regiones benéficas portadora de salud; y tempranamente desde niños [este hálito] los conduzca, inadvertidamente, a la semejanza, la amistad y la consonancia con la bella razón [tô̂ kaloî lógoi]?

- Los jóvenes guardianes terminan este período de instrucción habiéndose vuelto capaces de reconocer la belleza de los cuerpos y apreciarla, pero sólo en tanto esté acompañada por la belleza del alma (3. 402d1-e1), rechazando el mantener relaciones sexuales con individuos bellos (3. 403a7-b3).

- Sumado a esto, ellos poseen la aptitud de reconocer las características universales de las virtudes morales en instancias particulares (3. 402b9-c8), lo cual requiere, según leemos en 4. 444e4-5, que se hayan familiarizado con bellos hábitos y ocupaciones (tà kalà epitedeúmata).

En otras palabras, la educación temprana de los guardianes en general, y la educación artística o mousiké en particular, adiestran las corrientes de deseo de los individuos de modo tal que se los capacita para identificar la belleza física y moral, de manera similar a como se planteaba en el ascenso erótico del Banquete, ${ }^{56}$ haciendo crecer en ellos el deseo de lo bello de la parte racional, tal como leemos en 3. 403c6-7: "Y, supongo, es necesario que las cuestiones artísticas culminen en las cosas referentes al amor por la belleza [eis tà toû kaloû erotiká ]".

3 . 3. La educación superior para el desarrollo del deseo por la verdad: el conocimiento de las bellas ciencias y del Bien

Una vez finalizado este periodo de instrucción primaria, los educandos son ahora poseedores de una apropiada configuración de sus fuentes de motivación y han adquirido una primera comprensión sobre lo bello. A continuación, de acuerdo con sus capacidades, se les abren ahora dos posibilidades:

- Los menos dotados para la actividad mental terminan allí su formación intelectual y pasan a ser parte del ejército. Con creencias

${ }^{56}$ Véase también 3. 401d5-402a4. 
verdaderas que orientan correctamente sus acciones y una natural afinidad con lo bello, la agresividad de lo irascible apropiadamente orientada contra los apetitos y los enemigos del estado, los apetitos restringidos, se aproximan lo más que les es posible a la satisfacción del deseo de lo bueno.

- Los más competentes intelectualmente gozan de las mismas ventajas, pero podrán además continuar, ya sin el obstáculo de los apetitos y con la ayuda de lo irascible, el desarrollo del deseo por la verdad a fin de alcanzar el conocimiento del Bien y convertirse en filósofos-reyes. ${ }^{57}$ Para esto se los educa a través de un curso de estudios superiores que claramente coincide con los dos últimos niveles del ascenso amoroso del Banquete: el desarrollo del amor a las bellas ciencias y a la Belleza en sí.

En estas etapas avanzadas de aprendizaje, el objetivo fundamental es intentar apartar el alma de los particulares sensibles y provocar un "giro" (peristrophé ..., periagogé, 7. 521c5-6) hacia el mundo inteligible a fin de hacerlos surgir como philósophoi o "amantes de la sabiduría", esto es, tal como leemos en el libro 5, individuos que creen en la existencia de las Ideas y que pueden ser conducidos al conocimiento de las mismas. ${ }^{58}$ Los filósofos están "enamorados del espectáculo de la verdad" (5. 475e3-4) — "hambrientos" de la sabiduría como un todo (5. 474c8-11; 5. 475c6-8) - y son capaces de distinguir la Belleza en sí de las cosas que participan en ella y viceversa, ${ }^{59}$ así como de contemplarla, sin quedar presos de los particulares sensibles como les ocurre a los "amantes de las opiniones" o philodóxoi. (5. 480a1-4). ${ }^{60}$ De este modo, mientras que la mayoría permanece en el estado cognoscitivo de "opinión" o dóxa —intermedio (metaxý) entre la ignorancia (ágnoia) y conocimiento (epistéme) (5. 478c6-e5)—, ellos acceden a un nuevo estado metaxý: la filosofía, que resulta ser, como el éros del Banquete, ${ }^{61}$ además de "intermedio", "intermediario" hacia la verdad. Esta pasión

${ }^{57}$ Sobre la selección de los guardianes, puede verse 3. 412 b8 y ss. Sobre cómo discriminar entre los guardianes quiénes podrán ser filósofos y quiénes no, véase principalmente $6.484 \mathrm{a} 1 \mathrm{y}$ ss.

${ }^{58}$ Contrariamente a los "amantes de bellos sonidos y espectáculos", quienes no son capaces de reconocer lo bello en sí ni de seguir a alguien que pudiera conducirlos a este reconocimiento (5. 476c2-4).

\footnotetext{
${ }^{59}$ Véase $5.476 \mathrm{c} 9-\mathrm{d} 3$.

${ }^{60}$ Véase también 5. 476b4-8.

${ }^{61}$ Véanse las pp. 26-27, supra.
} 
del filósofo por la verdad y el verdadero bien es lo que le hará persistir en adquirir el conocimiento de lo que realmente es:

el que es realmente amante del aprendizaje [philomathés] está por naturaleza dispuesto a empeñarse por lo que es, y no permanecería en las muchas cosas que, en cada caso, se opina que son [toîs doxazoménois eînai], sino que iría y no se desanimaría ni desistiría de su pasión [toû érotos], hasta alcanzar la naturaleza de lo que es cada cosa en sí misma con aquello de su alma a lo cual corresponde alcanzar lo de tal condición - y que le corresponde connaturalmente. Con esta parte de su alma, [el amante del aprendizaje] tras intimar y mezclarse con lo que realmente es, y luego engendrar inteligencia y verdad, llegaría a conocer, verdaderamente viviría, se nutriría y así calmaría los dolores del parto, pero no antes. (6. 490a8-b7)

El currículo de estudios matemáticos y, luego, de práctica de la ciencia dialéctica, mayormente expuestos en el libro 7 de República, describe los pasos para que el filósofo ascienda a su objeto de deseo: la verdad y el Bien. ${ }^{62}$

a) En primer lugar, se requiere la práctica por un largo período de tiempo (7. 537b2-d8), y del modo correcto, de las ciencias matemáticas - como la aritmética, la geometría, la estereometría, la astronomía y la armonía (7. 522c1-531e1). El modo en que se realiza este aprendizaje nos permite comprender mejor en qué consiste el penúltimo estadio de la scala amoris del Banquete, donde se conocía lo bello común a todas las ciencias, así como la unidad de las mismas. También aquí, aquel que se ha conducido correctamente comprende la comunidad y parentesco (koinonían... kaì syggéneian, 7. 531c9-d4) de las bellas ciencias, y aprende a identificar una forma de belleza más plena. De hecho, estos estudios tienen como objetivo ayudar al alma en la búsqueda de lo que es bello y bueno (pròs tèn toû kaloû kaì agathoû zétesin, 7. 531c6-7). A través de estas bellas ciencias, el individuo se entrena para reconocer lo que es invariable y común a la multiplicidad de los particulares y aprende a razonar sobre estas entidades inmutables, de modo que el

${ }^{62}$ Dado que el esquema de la línea dividida (6. 509d6-511e4) y la alegoría de la caverna (7. 514a1 y ss.) no son exactamente equivalentes en terminología y simbolismo, describiremos el objetivo de los estudios de matemática y dialéctica para mayor simplicidad en relación con el paradigma de la línea, que es más obviamente epistemológico, a diferencia de la alegoría, que es más rica y envuelve también alusiones éticas y existenciales. Sin embargo, para referirnos al último principio utilizaremos, en cambio, los tres esquemas de la República: el del sol, el de la línea y el de la caverna.

Diánoia, vol. LIII, no. 60 (mayo 2008). 
alma es purificada (7. 527d5-e6) y se conocen los fundamentos de las artes vinculadas al mundo de la generación (7. 533b3-c5; 7. 522c58). La persona adiestrada en estas disciplina puede incluso llegar a la comprensión de la unidad, comunidad y afinidad de todas estas ciencias (7. 531d1-3) y, especialmente en el caso de la astronomía, de una belleza diferente y superior a la grandiosa pero, al fin y al cabo, visible, y, por lo tanto imperfecta, belleza de los cielos (7. 529c7-d5). Tal como en la diánoia o "entendimiento" descrita en el paradigma de la línea (6. 510b4-511a1), en este estadio prácticamente no hay relación con los particulares sensibles, sino una comprensión puramente intelectual entre principios aún hipotéticos; sin embargo, a diferencia de la diánoia de la línea dividida, el interés en los estudios matemáticos está aquí puesto más bien en "ascender" hacia el fundamento común de todas las ciencias que en el "descenso" a conclusiones obtenidas deductivamente a partir de esos principios.

b) La última etapa del programa de estudios de los guardianes nos permite, asimismo, una comprensión más amplia del estadio final en la escalera amorosa del Banquete, en la que se accede a un conocimiento mayor: el de la Belleza, la cual no depende de ninguna de sus instancias y es fundamento absoluto de las cosas bellas. Tras la educación matemática, realizada del modo antes descrito, la persona está lista para moverse a la adquisición de la ciencia suprema de la dialéctica (mégiston máthema, 6. 504e4-5; d2-3). Ésta consiste en lograr una visión panóptica de la interrelación entre las esencias de las cosas con fundamento en la Idea del Bien, en forma similar a la noésis o "intelección" de la última sección de la línea, en la cual la mente opera absolutamente sin representaciones sensibles y abandona los supuestos para moverse hacia un principio que no requiera a su vez fundamentación, y que podemos identificar con lo Bueno (6. 510b4-9; 6. 511b3-c2; 7. 533c7-e2), lo cual excede en belleza incluso al conocimiento y la verdad (6. 509a68). La caracterización del Bien en la alegoría del sol y la caverna, como último principio en tres sentidos - causa epistemológica, en cuanto que otorga inteligibilidad y verdad a las cosas (6. 508d4-509a5); causa ontológica en cuanto que otorga existencia a las cosas (6. 509b7-8); y fundamento ético en cuanto que la sabiduría es el fundamento de las restantes virtudes, tales como la valentía, la moderación e incluso la justicia (6. 504d6-505b3) ${ }^{63}$ - también nos permite interpretar en qué

${ }^{63}$ Con referencia a este punto, véase Irwin 1995, pp. 311-313. Esto se relaciona con el problema de la unidad de la virtud, que ya aparece en los diálogos tempranos, el cual no podemos considerar en el presente trabajo. 
sentido la Belleza es fundamento de las cosas hermosas, tal como se afirma, pero no se explica, en el Banquete.

\section{Conclusión}

Hemos visto, entonces, en la República cómo la teoría del alma tripartita desarrolla más extensamente la idea del Banquete de la constitución de cada ser humano en el éros, así como en qué consiste la universalidad del deseo de lo verdaderamente bueno. También se demostró cómo el programa de educación, diseñado para configurar apropiadamente las corrientes de deseo y permitir el máximo desarrollo del amor a la verdad de la parte racional, es una expansión de la "escalera amorosa" del Banquete. En otras palabras, según la concepción platónica del ser humano que encontramos anunciada en el Banquete y desarrollada en la República, lo que esencialmente somos y nos constituye es el desarrollo de nuestro deseo de la sabiduría. Pero para que el liderazgo del éros filosófico sea posible, se requiere una determinada organización de todas las fuentes de motivación - representadas en las tres partes del alma-, de modo que los apetitos sean reducidos al límite de lo necesario, la agresividad colabore con los objetivos de la razón, y lo racional se vuelva afín a lo bello y lo bueno, e incluso, si fuera posible, llegue posteriormente a conocer la Belleza y el Bien y a obrar de un modo verdaderamente virtuoso, con sostén en este conocimiento. Esta estructura psíquica se logra a través de una apropiada educación temprana dirigida a los tres aspectos del alma y una educación superior que desarrolla al máximo, a través del estudio de las ciencias matemáticas y la dialéctica, el amor a la sabiduría de la razón. Aquel que fuera capaz de ser conducido correctamente en este "ascenso", abandonando lo más que pueda las "cadenas" de su existencia corpórea mortal, es quien más se acerca a la condición de los dioses, poseedores permanentes de lo verdaderamente bueno.

Estas conclusiones también pueden ser utilizadas productivamente para realizar una lectura integradora del Fedro, ${ }^{64}$ en cuanto que allí podrían verse sintetizadas las ideas del Banquete y la República respecto del éros, al mismo tiempo que se las extiende a una concepción del amor que abarca el universo entero. ${ }^{65}$

${ }^{64}$ De este diálogo se ha criticado su falta de unidad. Respecto a este problema, véanse Rowe 1986; Heath 1987, y Rowe 1987.

${ }^{65}$ Mientras que el discurso de Lisias que repite Fedro (Fedr. 230e6-234c5) y el primer discurso de Sócrates (Fedr. 237b2-241d1) refieren a éros en su sentido habitual como enamoramiento por otro individuo, el segundo discurso de Sócrates

Diánoia, vol. LIII, no. 60 (mayo 2008). 


\section{BIBLIOGRAFÍA}

1. Obras de referencia

$$
\begin{aligned}
D K= & \text { H. Diels y W. Kranz, Die Fragmente der Vorsokratiker, 6a. ed., Weid- } \\
& \text { mann, Berlín, 1951-1952. } \\
D R A E= & \text { Diccionario de la Real Academia Española, 22a. ed., Real Academia } \\
& \text { Española, Madrid, 2001. } \\
L S J= & \text { H.G. Liddell, D.D. Scott y H.S. Jones, 9a. ed., Greek English Lexicon, } \\
& \text { Clarendon, Oxford, 1940. } \\
T L G= & \text { Thesaurus Linguae Graecae: A Digital Library of Greek Literature, } \\
& \text { recurso electrónico, base de datos en línea, University of California, } \\
& \text { Irvine, 2001. }
\end{aligned}
$$

\section{Obras específicas}

Adam, J., 1965, The Republic of Plato, Cambridge University Press, Cambridge, 2 vols.

Annas, J., 2003, Plato: A Very Short Introduction, Oxford University Press, Oxford.

(Fedr. 243e9-257a2) retoma y despliega desde otro ángulo la concepción de éros que se acuña en el Banquete como la corriente de deseo que impulsa nuestra existencia toda en una determinada dirección y que, idealmente, debería expresarse como filosofía y elevarnos a la contemplación de las Ideas. La imagen del carro alado del segundo discurso sintetiza, a su vez, lo desarrollado en la República con respecto a cómo la configuración erótica final de un individuo y la posibilidad de liderazgo de la razón dependen del modo en que se organizan sus fuentes primarias de motivación. Por otra parte, el mito del carro alado (Fedr. 246a3 y ss.), al simbolizar el periplo más o menos exitoso del alma humana, una vez que abandona su encarnación en un cuerpo mortal, hacia el lugar supraceleste de las Ideas, reedita la consideración del alma en su destino inmortal a la luz de cuánto ha desplegado su deseo de sabiduría. Asimismo, la imagen de la caravana de los dioses con sus propios carros, quienes nunca fracasan en el acceso al lugar "fuera del cielo" y contemplan la realidad eidética de modo periódico (Fedr. 247d5 y ss.), explicita aún más la idea de inmortalidad divina a la que el hombre trata, limitadamente, de aproximarse (véase la n. 7 , supra). Por otra parte, dado que el itinerario de las almas divinas simboliza probablemente el movimiento regular de los astros, esto permite proyectar la idea de un éros cósmico del cual el éros humano es parte. La segunda parte del Fedro (Fedr. 257b7-279c8), dedicada fundamentalmente a una crítica de la retórica desde la dialéctica filosófica, adquiere más profunda resonancia si se la considera a la luz de los desarrollos de la primera parte. Practicar la dialéctica filosófica e inducirla en otros significa, desde otro contexto, contribuir al desarrollo del deseo de la verdad, en la medida de lo posible, y a la participación, a la manera de los dioses, en un éros que mueve el universo entero. Véase Fierro (en prensa). 
Annas, J., 1981, An Introduction to Plato's Republic, Oxford University Press, Oxford.

Bobonich, C., 2002, Plato's Utopia Recast: His Later Ethics and Politics, Oxford University Press, Oxford.

Bowen, A.C., 1988, "On Interpreting Plato", en Ch.L. Griswold Jr. (comp.), Platonic Writings. Platonic Readings, Routledge, Londres.

Burnet, I., 1905-1907, Platonis Opera, Clarendon, Oxford, 5 vols.

Carone, G.R., 2005, "Plato's Stoic View on Motivation", en R. Salles (comp.), Metaphysics, Soul and Ethics in Ancient Thought. Themes from the Work of R. Sorabji, Oxford University Press, Nueva York.

_, 2001, "Akrasia in the Republic: Does Plato Change his Mind?", Oxford Studies in Ancient Philosophy, vol. 20, pp. 107-148.

Cooper, J.M., 1999, "Plato's Theory of Human Motivation”, en Fine 1999, pp. 186-206.

Cornford, F.M., 1950, "The Doctrine of Eros in Plato's Symposium", en The Unwritten Philosophy and Other Essays, Cambridge University Press, Cambridge, pp. 68-81.

Davidson, J, 1997, Courtesans and Fishcakes: The Consuming Passions of Ancient Greece, Harper Collins, Londres.

Dover, K.J., 1980, Plato: Symposium, Cambridge University Press, Cambridge.

_, 1978 , Greek Homosexuality, Harvard University Press, Cambridge, Mass.

Fierro, M.A., 2007, "El concepto de metaxý en el Banquete de Platón", en J. Martínez Contreras (comp.), El saber filosófico (Actas del Simposio de Filosofía Antigua, XIII Congreso de Filosofía, Morelia, México), Asociación Filosófica de México/Siglo XXI, México, pp. 249-254.

— , 2001a, "Symp. 212a2-7: Desire for the Truth and the Desire for Death and a God-Like Immortality", Méthexis, vol. 14, pp. 23-43.

— , 2001b, "Narrar el verdadero amor", en V. Julia (comp.), Los antiguos griegos y su lengua, Biblos, Buenos Aires, pp. 23-38.

- (en prensa), "La concepción universal del éros", en Actas del XIV Congreso Internacional de Filosofía 'Identidad y diferencia", realizado en Mazatlán, Sin., del 4 al 10 de noviembre de 2007.

Fine, G. (comp.), 1999, Plato 2. Ethics, Politics, Religion, and the Soul, Oxford University Press, Oxford.

Foucault, M., 1982, Historia de la sexualidad, trad. de U. Guinazu, Siglo XXI, México.

Frede, D., 1993, "Out of the Cave: What Socrates Learned from Diotima", en R.M. Rosen y J. Farrell (comps.), Nomodeiktes: Greek Studies in Honour of Martin Oswald, University of Michigan Press, Ann Arbor, pp. 397-422.

Gill, C., 1996, Personality in Greek Epic, Tragedy, and Philosophy, Clarendon, Oxford.

—, 1985 , "Plato and the Education of Desire", Archive für Geschichte der Philosophie, vol. 67, pp. 1-26.

Hackforth, R, 1950, "Immortality in Plato's Symposium", The Classical Review, vol. 64, pp. 43-45.

Diánoia, vol. LIII, no. 60 (mayo 2008). 
Halperin, D.M., 1992, "Plato and the Erotics of Narrativity", Oxford Studies in Ancient Philosophy, volumen suplementario, pp. 113-129.

Heath, M., 1987, "The Unity of Plato's Phaedrus", Oxford Studies in Ancient Philosophy, vol. 7, pp. 150-173, 189-191.

Hobbs, A., 2000, Plato and the Hero, Cambridge University Press, Cambridge. Hoffman, P., 2005, "Plato on Appetitive Desires in the Republic", Apeiron, vol. 36, pp. 171-174.

Hornsby, R., 1956-1957, "Significant Action in the Symposium", Classical Journal, vol. 52, pp. 37-40.

Hunter, R., 2004, Plato's Symposium, Oxford University Press, Oxford.

Irwin, T., 1995, Plato's Ethics, Oxford University Press, Oxford. [Versión en castellano: La ética de Platón, trad. Ana Isabel Stellino, Instituto de Investigaciones Filosóficas-UNAM, México, 2000.]

Jaeger, W.W., 1942, Paideia: los ideales de la cultura griega, trad. J. Xirau, Fondo de Cultura Económica, México.

Janaway, C., 1995, Images of Excellence. Plato's Critique of the Arts, Oxford University Press, Oxford.

Kahn, Ch.H., 1996, Plato and the Socratic Dialogues: The Philosophical Use of a Literary Form, Cambridge University Press, Cambridge.

_, 1987 , "Plato's Theory of Desire”, Review of Metaphysics, vol. 41, pp. 77103.

Lorenz, H., 2004, "Desire and Reason in Plato's Republic", Oxford Studies in Ancient Philosophy, vol. 27, pp. 83-116.

Moline, J., 1978, "Plato and the Complexity of the Psyche", Archiv für Geschichte der Philosophie, vol. 60, pp. 1-26.

Murphy, N.R., 1951, The Interpretation of Plato's Republic, Clarendon, Oxford.

Nussbaum, M., 1986, The Fragility of Goodness: Luck and Ethics in Greek Tragedy and Philosophy, Cambridge University Press, Cambridge.

O’Brien, M.J., 1984, “'Becoming Immortal' in Plato's Symposium”, en D.E. Gerber (comp.), Greek Poetry and Philosophy: Studies in Honour of Leonard Woodbury, Chico, CA, pp. 185-205.

Parry, R.D., 1996, Plato's Craft of Justice, State University of New York Press, Albany, NY.

Penner, T., 1971, "Thought and Desire in Plato", en G. Vlastos (comp.), A Collection of Critical Essays, vol. II, Doubleday, Nueva York, pp. 96-118.

Price, A.W., 1995, Mental Conflict, Routledge, Londres/Nueva York.

Raven, J.E., 1965, Plato's Thought in the Making, Cambridge University Press, Cambrige.

Robin, L., 1908, La Théorie platonicienne de l'amour, Presses Universitaires de France, París.

Robinson, T.M., 1995, Plato's Psychology, 2a. ed., University of Toronto Press, Toronto.

Rowe, C.J., 1998, Plato: Symposium, Aris and Phillips, Warminster.

— 1987 , "The Unity of the Phaedrus: A Reply to Heath", Oxford Studies in Ancient Philosophy, vol. 7, pp. 175-188. 
Rowe, C.J., 1986, “The Argument and Structure of Plato's Phaedrus", Proceedings of the Cambridge Philological Society, vol. 32, pp. 106-125.

Santas, G., 1988, Plato and Freud. Two Theories of Love, Basil Blackwell, Oxford.

Sedley, D., 1999, "The Ideal of Godlikeness", en Fine 1999, pp. 309-328.

Segvic, H., 2000, "No One Errs Willingly. The Meaning of Socratic Intellectualism", Oxford Studies in Ancient Philosophy, vol. 19, pp. 1-45.

Souilhé, J., 1919, La Notion platonicienne d'intermédiaire dans la philosophie des dialogues, Félix Alcan, París.

Recibido el 28 de junio de 2006; aceptado el 11 de noviembre de 2007. 